\title{
Molecular conformation of then published Ziziphus budhensis and its religious and economic values
}

\begin{abstract}
M. L. Pathak ${ }^{1 *}$, H. C. Li ${ }^{1}$, B. Xu' ${ }^{1}$ X. F. Gao ${ }^{1}$, K. K. Pokharel ${ }^{2}$ and A. B. Nagarkoti ${ }^{3}$
The newly described species, Ziziphus budhensis was confirmed as Chinese Jujuba, Z. xiangchengensis on the basis of their DNA analyses. Z. budhensis was explained as a new species on the basis of some morphological differences in 2015. In the Year 2016, the DNA samples were collected from the type locality of Nepal, and the molecular analyses were carried out. The type specimens and the other available images from the different herbariums were examined. Besides, the protologue and the type images were studied carefully. The result showed that though there were some differences in the habit and the habitat of the plant, the previously described new species, Z. budhensis was found to be same as the Chinese species, $Z$. xiangchengensis. This study also showed the importance of the molecular work of $Z$. budhensis and confirmed it morphologically distinct although it was very close to the Chinese species.
\end{abstract}

Key words: Molecular conformation, Rhamnaceae, Ziziphus budhensis, Z. xiangchengensis

$\mathrm{T}$ he genus, Ziziphus is characterized as warmtemperate and subtropical plant. The plants are mostly shrubs or small to medium-sized trees, erect or straggling, often climbing, evergreen or deciduous, often spinose with alternate leaves (Chen and Schirarend, 2007). There are about 100 Ziziphus species reported throughout the world (Mabberley, 2008); the number has been reported up to 170 species (Islam and Simmons, 2006). Among them, 17 species are reported from India (Bhandari and Bhansali, 2000), 12 from China (Chen and Schirarend, 2007), 7 from Bhutan (Grierson and Long, 1991) and 7 including $Z$. budhensis are reported from Nepal (Bhattarai and Pathak, 2015; NHPL, 2011; NHPL, 2012). So far, about 275 names (including all taxa) under the genus, Ziziphus have been reported (TPL, 2013). Most of the Ziziphus fruits are edible (Outlaw Jr. et al., 2002).

The most commonly named "Bodhichitta" or "Buddha Mala", a new and endemic species to Nepal in 2015 was described as Ziziphus budhensis. The name was honored to Lord Buddha, the light of Asia, born in Lumbini, Nepal before $2500 \mathrm{BC}$. At that time, the species was also compared with some species reported from China. However, due to some morphological differences,

the species was explained as a new species. This year, the DNA samples were collected from the type locality of Nepal, and the molecular analyses were carried out. The type images and the other available images together with the specimen from China were re-examined. The result showed that though there are some differences in the habit and habitat, the previously described new species was found to be the same as the Chinese species, xiangchengensis.

\section{Taxonomic description and distribution}

Ziziphus xiangchengensis $\mathrm{Y}$. L. Chen and P. K. Chou, Bull.Bot. Lab. N. E. Forest. Inst., Harbin 5: 88. 1979.

Ziziphus budhensis Bhattarai and M.L. Pathak. Indian J. P1. Sci. [Jaipur] 4 (2): 73.2015

$Z$. xiangchengensis is a spinose $2-3 \mathrm{~m}$, sometimes up to $8 \mathrm{~m}$ tall small trees or shrub. Stem- glabrous; young branches- red-brown, densely pilose whereas old branches- gray-brown, flexuose, glabrous, old branches without spines. Leaves alternate, or 2 or 3 in fascicles; stipular spines 2 , both erect or one recurved, $1-1.6 \mathrm{~cm}$, slender; petiole $5-8 \mathrm{~mm}$, sometimes up to $10 \mathrm{~mm}$, sparsely pilose; leaf blade abaxially pale green, adaxially dark green, ovate or ovate-oblong, 2-4 $\mathrm{cm} \times$

\footnotetext{
${ }^{1}$ Chengdu Institute of Biology, Chinese Academy of Sciences, Chengdu, Post code: 610041, China. *E-mail: mitra@cib.ac.cn

${ }^{2}$ Department of Forest Research and Survey, Kathmandu, Nepal

${ }^{3}$ Freelance Researcher, Godawari Municipality, Lalitpur
} 
$1.5-3 \mathrm{~cm}$, papery, abaxially glabrous to clustered hairy in vein axils, adaxially glabrous, 3-veined from base, veins prominent on both surfaces, mid-vein without conspicuous secondary veins, base asymmetric, sub-rounded, margin crenateserrate, apex obtuse or rounded. Flowers yellowgreen, few- to 10 , sometimes up to 14 , fascicled in axils of leaves, without peduncles. Pedicel 4-5 $\mathrm{mm}$, ferruginous pilose. Sepals ovate-triangular, densely ferruginous pubescent, apex acute. Petals 5 , creamy white, spatulate, cuccullate clawed, ca. $2 \mathrm{~mm}$, initiated along with stamen; stamens shorter than petals. Stamens pentandrous extrose, exserted, ca. $2 \mathrm{~mm}$, anther 2 lobed cordate dorsi fixed. Ovary globose, glabrous; style 2-fid (rarely 3 -fid), drupe yellow-green, globose, generally 1.2 (sometimes $0.6 \mathrm{~cm}$ ) x $1.5 \mathrm{~cm}$ in diam; apex mисronulate, with persistent calyx tube at base; fruiting pedicel 5-7 $\mathrm{mm}$, sparsely pilose; mesocarp thin $(0.5-1 \mathrm{~cm})$, corky; endocarp cartilaginous; stone ca. $4 \mathrm{~mm}$, 2-loculed and with 2 seeds. Seeds compressed, convex on one face, obovoid, ca. 6-10 mm, sometimes up to $15 \mathrm{~mm}$. Flowering in March-April and fruiting in JulyAugust (Fig. 1A and 1B).

Z. xiangchengensis is rarely distributed in West Sichuan (Xiangcheng) and the Yunnan Province of China $(2,200-2,800 \mathrm{~m})$ and a few places of central Nepal (1,000-2,000 m). One of the interesting facts about the distribution is that, this plant is reported only in the two places of China, viz. the Sichuan Province and the Yunnan Province, and there are only four specimens (including types) at Chengdu Institute of Biology (CDBI), six specimens at Kunming Herbarium (KUN) and very few are at National Herbarium of China (PE). The distribution is very limited; however, the presence of this plant in the Tibet Autonomous Region is under investigation. Due to this, the previous fact regarding the evolution of this species is quite mysterious.

Note: The description of the plant is based on the type literature of $Z$. xiangchengensis (Chen and Chou, 1979), the type literature of $Z$. budhensis (Bhattarai and Pathak, 2015) and the Flora of China (2007).
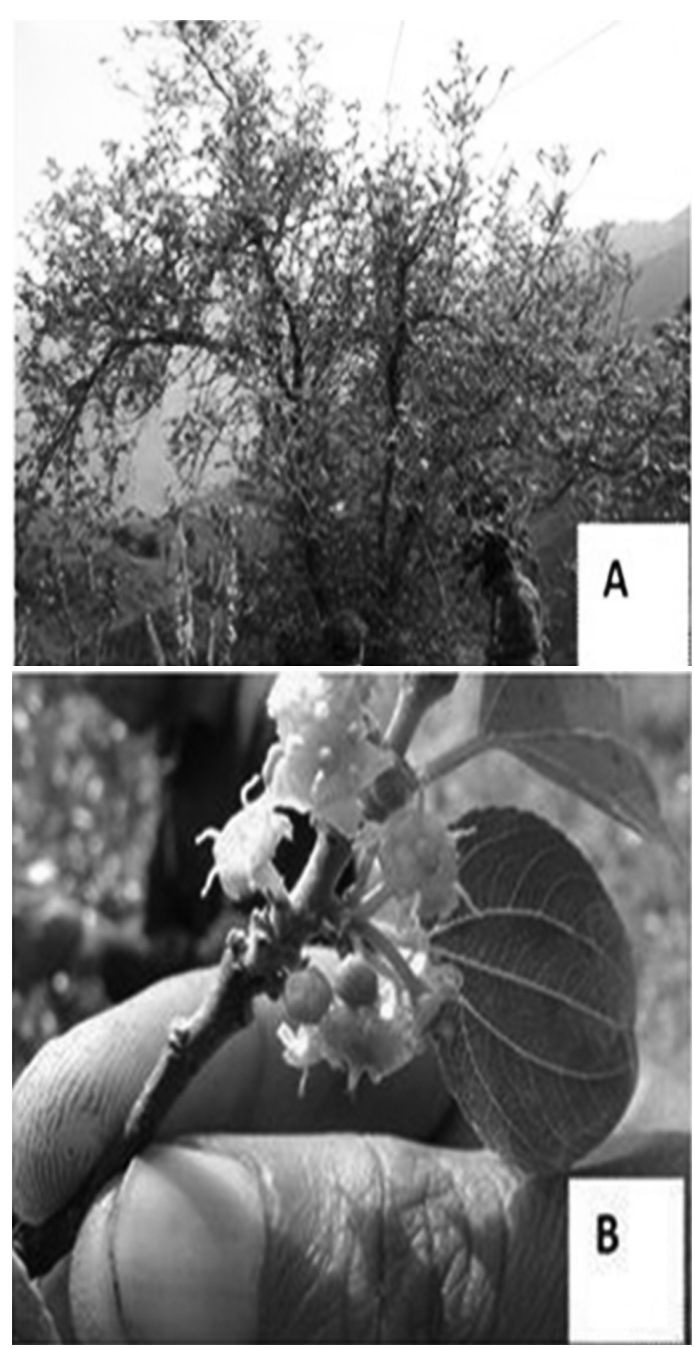

Fig. 1: A tree of $Z$. budhensis (A) and its Flowering branch (B), Kharpakot (1,900 m), Kavrepalanchok District, Nepal

\section{Specimen Examined}

- The Holotype and the Isotype of Z. budhensis, KATH, C. N. 20701, Kharpakot (1,900 m), Kavrepalanchok District, (Fig. 2) and

- Holotype and Isotype of Z. xiangchengensis, CDBI, C. N. 2994, Xiancheng, Sichuan (2,800 m), 1979, China. (Fig. 3) 


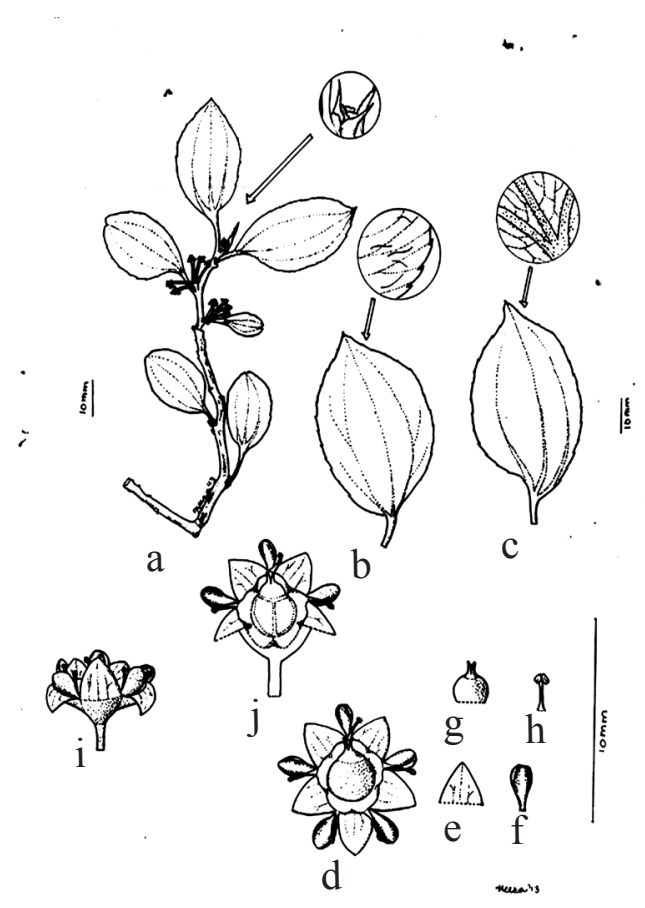

Fig. 2: Fertile branch of $Z$. budhensis with flowers (a); Leaf dorsal side X1 (b); Leaf ventral side X1 (c); Flower X6 (d); Sepal X6 (e); Petal X6 (f); Gynoecium and Ovary X6 (g); Stamen X6 (h); A flower with sepals and petals with stamens $\times 6$ (i) and Longitudinal section of a flower X6 (j), KATH Holotype: C.N. 20701 (1,900 m), Source: Bhattarai and Pathak (2015)

\section{Methodology}

A small piece of young leaves sample was collected from the type locality of $Z$. budhensis, Kavrepalanchok district of central Nepal (KATH Holotype: C.N. 20701, 1,900 m). DNA was extracted from the silica-dried material fragments using the TIANGEN plant genomic DNA extraction kit (TIANGEN Biotech., Beijing, China) following the manufacturers' protocols. The internal transcribed spacer (ITS): ITS-A and ITS-B were used as primer in this study.

PCR was carried out following the same methods as $\mathrm{Xu}$ et al. (2013). The amplified fragments were purified with the TIAN quick Mini Purification Kit (TIANGEN). The sequencing of the purified PCR products was done by the help of Invitrogen (Shanghai, China). The Sequencher 4.1 (Gene Codes Corp., Ann Arbor, MI, USA) was used to assemble and edit complementary strands. The sequences obtained for each fragment were initially aligned using Clustal X 1.8181.

The DNA sequences obtained from the Company were edited using the Sequencer 4.4. The edited sequence was blasted in ncbi (www.ncbi.nlm. nih.gov) and aligned. For phylogenetic tree, the model suggested by Tamura and Nei (1993) was selected. The aligned sequences were used to make a phylogenetic tree using MWGA6 (Tamura et al., 2013). A maximum likelihood tree (Fig. 4) was constructed, and the maximum parsimony was also observed.
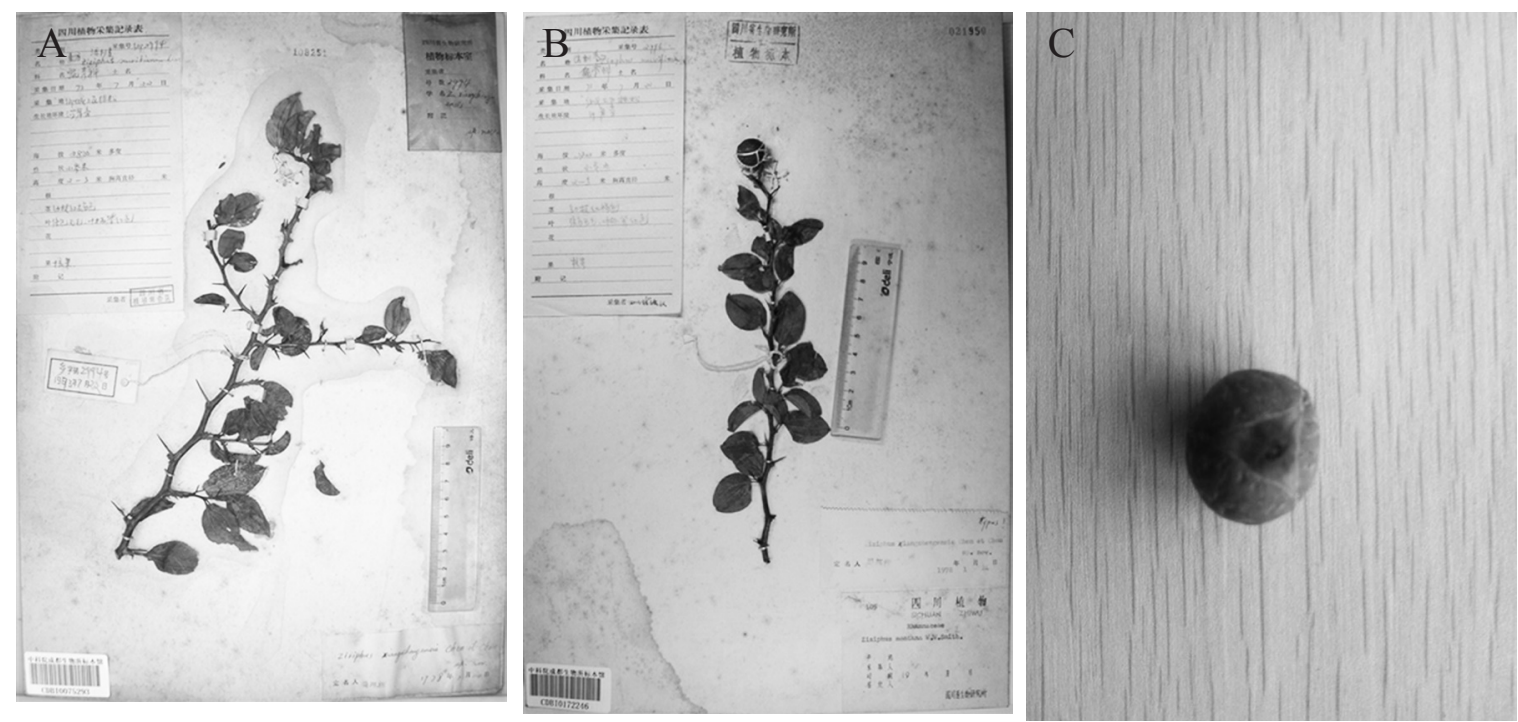

Fig. 3: The type images of $Z$. xiangchengnensis deposited at the CDBI, CN 2994 Chengdu Institute of Biology, Chengdu, China (A and B) and its three faced-seed (C)

(Source: www.cvh.org.cn) 


\section{Results}

To show the genetic differences, Maximum Likelihood Methods are shown in Fig. 4. Table 1, below demonstrates the pair-wise distances among the different Ziziphus species. The genetic difference between $Z$. budhensis and $Z$. xianchengnensis was found to be only 0.004 . The molecular result was also compared with that of Li et al. (2009). The findings revealed that they were almost the same species. Later on, the type specimens of $Z$. xianchengnensis (Fig. 3: A, B, C) were examined at the Chendgu Institute of Biology (CDBI), which were almost the same as that of $Z$. budhensis from Nepal. When this species was described for the first time, there was no any information about the flower characters. This time, a full description has been provided with flower and fruit characters.

Though there were some differences about the habit, distribution and shape of some flowering parts between the two type descriptions, the important characters- the faces of the seeds and the convex shape on one side of the seeds were remarkable. The DNA analysis showed almost no difference at all while the morphological differences might be due to the different habitats and the other environmental factors. The detail description of the species is given under the taxonomic description.

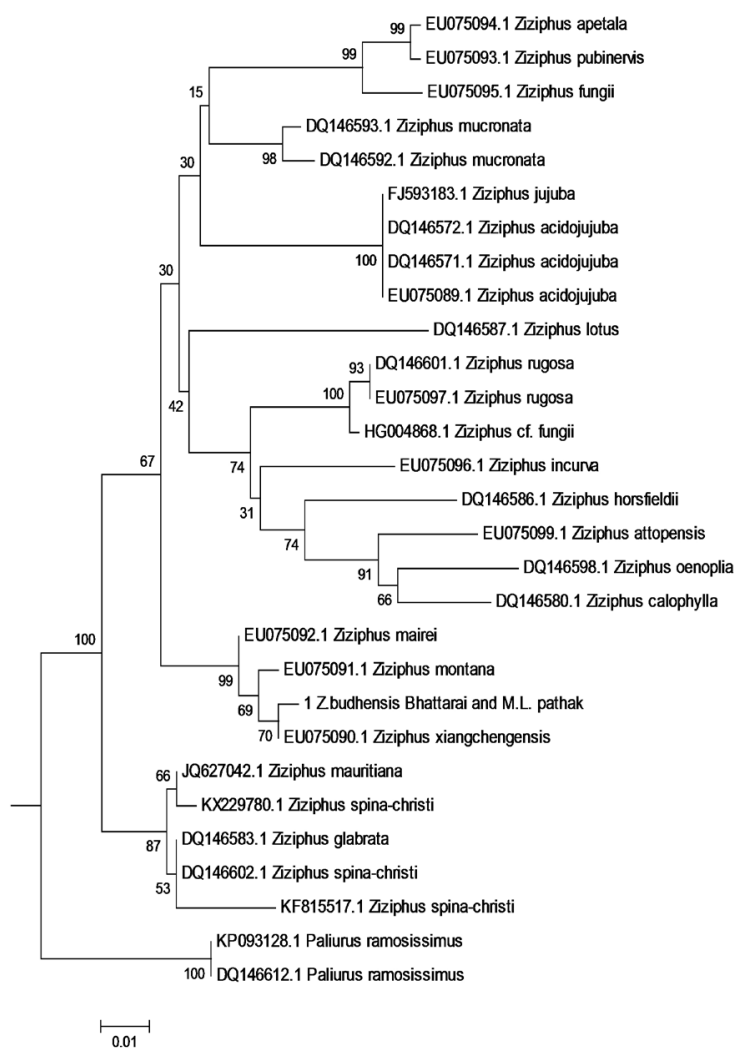

Fig. 4: Molecular phylogenetic analysis using the maximum likelihood method

The evolutionary history was inferred by using the Maximum Likelihood Method based on the Tamura-Nei Model [1]. The tree with the highest $\log$ likelihood (-2050.2307) is shown. The initial trees for the heuristic search were obtained

Table 1: Pair-wise distances among the Ziziphus species

\begin{tabular}{|c|c|c|c|c|c|c|c|c|c|c|c|c|c|c|c|c|c|c|c|c|c|c|c|c|c|c|c|c|}
\hline 1_Z.budhensis & & & & & & & & & & & & & & & & & & & & & & & & & & & & \\
\hline EU075090.__Zziphus_xiangchengensis & 0.0040 & & & & & & & & & & & & & & & & & & & & & & & & & & & \\
\hline EU075092.__Zziphus_mairei & 0.0081 & 0.0081 & & & & & & & & & & & & & & & & & & & & & & & & & & \\
\hline EU075091.__Zziphus_montana & 0.0122 & 0.0081 & 0.0081 & & & & & & & & & & & & & & & & & & & & & & & & & \\
\hline DQ146593.1_Zziphus_muccronata & 0.0439 & 0.0439 & 0.0352 & 0.0417 & & & & & & & & & & & & & & & & & & & & & & & & \\
\hline J0627042.1_Zziphus_maurtiana & 0.0481 & 0.0481 & 0.0436 & 0.0459 & 0.0523 & & & & & & & & & & & & & & & & & & & & & & & \\
\hline DQ146583.1_Zzizhus__labrata & 0.0481 & 0.0481 & 0.0436 & 0.0459 & 0.0523 & 0.0040 & & & & & & & & & & & & & & & & & & & & & & \\
\hline DQ146602.1_Zzizhus_sping-christi & 0.0481 & 0.0481 & 0.0436 & 0.0459 & 0.0523 & 0.0040 & 0.0000 & & & & & & & & & & & & & & & & & & & & & \\
\hline FJ593183.__Zziphus_jujuba & 0.0639 & 0.0639 & 0.0591 & 0.0616 & 0.0545 & 0.0659 & 0.0659 & 0.0659 & & & & & & & & & & & & & & & & & & & & \\
\hline DQ146572.1_Ziziphus_acidojujuba & 0.0639 & 0.0639 & 0.0591 & 0.0616 & 0.0545 & 0.0659 & 0.0659 & 0.0659 & 0.0000 & & & & & & & & & & & & & & & & & & & \\
\hline DQ146592.1_Zzizhpus_mucronata & 0.0526 & 0.0526 & 0.0438 & 0.0504 & 0.0101 & 0.0502 & 0.0502 & 0.0502 & 0.0568 & 0.0568 & & & & & & & & & & & & & & & & & & \\
\hline DQ146571.1_Zziphus_acidojijuba & 0.0639 & 0.0639 & 0.0591 & 0.0616 & 0.0545 & 0.0659 & 0.0659 & 0.0659 & 0.0000 & 0.0000 & 0.0568 & & & & & & & & & & & & & & & & & \\
\hline DQ146601.___ziphous_ugosa & 0.0620 & 0.0620 & 0.0552 & 0.0576 & 0.0615 & 0.0619 & 0.0619 & 0.0619 & 0.0777 & 0.0777 & 0.0639 & 0.0777 & & & & & & & & & & & & & & & & \\
\hline DQ146586.1_ZZziphus_horsfieldii & 0.0776 & 0.0776 & 0.0706 & 0.0732 & 0.0679 & 0.0704 & 0.0661 & 0.0661 & 0.0913 & 0.0913 & 0.0678 & 0.0913 & 0.0682 & & & & & & & & & & & & & & & \\
\hline EU075089.1_Zzizhous_acidojujuba & 0.0639 & 0.0639 & 0.0591 & 0.0616 & 0.0545 & 0.0659 & 0.0659 & 0.0659 & 0.0000 & 0.0000 & 0.0568 & 0.0000 & 0.0777 & 0.0913 & & & & & & & & & & & & & & \\
\hline DQ146598.1_Zziphus_oenoplia & 0.0893 & 0.0844 & 0.0845 & 0.0823 & 0.0842 & 0.0755 & 0.0755 & 0.0755 & 0.1155 & 0.1155 & 0.0843 & 0.1155 & 0.0733 & 0.0706 & 0.1155 & & & & & & & & & & & & & \\
\hline KF815517.1_Zzizphus_spina-christi & 0.0617 & 0.0617 & 0.0570 & 0.0594 & 0.0659 & 0.0247 & 0.0206 & 0.0206 & 0.0800 & 0.0800 & 0.0684 & 0.0800 & 0.0760 & 0.0849 & 0.0800 & 0.0997 & & & & & & & & & & & & \\
\hline HG004868.1_ZZziphus_cf._fungii & 0.0597 & 0.0597 & 0.0529 & 0.0553 & 0.0592 & 0.0662 & 0.0662 & 0.0662 & 0.0775 & 0.0775 & 0.0616 & 0.0775 & 0.0061 & 0.0658 & 0.0775 & 0.0754 & 0.0803 & & & & & & & & & & & \\
\hline KC229780.1_Ziziphus_spins-christi & 0.0481 & 0.0481 & 0.0436 & 0.0459 & 0.0523 & 0.0040 & 0.0081 & 0.0081 & 0.0659 & 0.0659 & 0.0502 & 0.0659 & 0.0619 & 0.0704 & 0.0659 & 0.0800 & 0.0289 & 0.0662 & & & & & & & & & & \\
\hline DQ146580.1_Zzizhus_calophylla & 0.0827 & 0.0827 & 0.0756 & 0.0782 & 0.0728 & 0.0752 & 0.0752 & 0.0752 & 0.0918 & 0.0918 & 0.0725 & 0.0918 & 0.0684 & 0.0589 & 0.0918 & 0.0438 & 0.0993 & 0.0660 & 0.0752 & & & & & & & & & \\
\hline EU075097.1_Zziphus__ugosa & 0.0620 & 0.0620 & 0.0552 & 0.0576 & 0.0615 & 0.0619 & 0.0619 & 0.0619 & 0.0777 & 0.0777 & 0.0639 & 0.0777 & 0.0000 & 0.0682 & 0.0777 & 0.0733 & 0.0760 & 0.0061 & 0.0619 & 0.0684 & & & & & & & & \\
\hline DQ146587.1_Ziziphus_lotus & 0.0709 & 0.0709 & 0.0662 & 0.0732 & 0.0682 & 0.0751 & 0.0751 & 0.0751 & 0.0935 & 0.0935 & 0.0705 & 0.0935 & 0.0872 & 0.0987 & 0.0935 & 0.0919 & 0.0942 & 0.0848 & 0.0795 & 0.0825 & 0.0872 & & & & & & & \\
\hline KPO93128.1_Pallurus_ramosissimus & 0.0770 & 0.0770 & 0.0701 & 0.0770 & 0.0747 & 0.0610 & 0.0610 & 0.0610 & 0.0935 & 0.0935 & 0.0726 & 0.0935 & 0.0934 & 0.0978 & 0.0935 & 0.1013 & 0.0842 & 0.0954 & 0.0654 & 0.0937 & 0.0934 & 0.1007 & & & & & & \\
\hline EU075099.__Zzizhius_attopensis & 0.0756 & 0.0756 & 0.0709 & 0.0735 & 0.0680 & 0.0662 & 0.0662 & 0.0662 & 0.1008 & 0.1008 & 0.0659 & 0.1008 & 0.0643 & 0.0638 & 0.1008 & 0.0462 & 0.0850 & 0.0619 & 0.0706 & 0.0439 & 0.0643 & 0.0847 & 0.0915 & & & & & \\
\hline EU075096._ZZziphus_incurva & 0.0686 & 0.0686 & 0.0617 & 0.0642 & 0.0634 & 0.0751 & 0.0751 & 0.0751 & 0.0774 & 0.0774 & 0.0658 & 0.0774 & 0.0528 & 0.0656 & 0.0774 & 0.0730 & 0.0894 & 0.0505 & 0.0751 & 0.0727 & 0.0528 & 0.0777 & 0.0956 & 0.0684 & & & & \\
\hline DQ146612.1_Paliurus_ramosissimus & 0.0770 & 0.0770 & 0.0701 & 0.0770 & 0.0747 & 0.0610 & 0.0610 & 0.0610 & 0.0935 & 0.0935 & 0.0726 & 0.0935 & 0.0934 & 0.0978 & 0.0935 & 0.1013 & 0.0842 & 0.0954 & 0.0654 & 0.0937 & 0.0934 & 0.1007 & 0.0000 & 0.0915 & 0.0956 & & & \\
\hline EU075094.1_Zziphus__petala & 0.0749 & 0.0749 & 0.0657 & 0.0682 & 0.0546 & 0.0612 & 0.0569 & 0.0569 & 0.0771 & 0.0771 & 0.0612 & 0.0771 & 0.0822 & 0.0959 & 0.0771 & 0.1103 & 0.0707 & 0.0865 & 0.0612 & 0.1058 & 0.0822 & 0.0909 & 0.0910 & 0.1006 & 0.0819 & 0.0910 & & \\
\hline EU075095.__Zzizhius_tungii & 0.0728 & 0.0728 & 0.0659 & 0.0684 & 0.0591 & 0.0660 & 0.0660 & 0.0660 & 0.0818 & 0.0818 & 0.0658 & 0.0818 & 0.0776 & 0.0957 & 0.0818 & 0.1083 & 0.0801 & 0.0819 & 0.0660 & 0.1080 & 0.0776 & 0.0866 & 0.0932 & 0.0985 & 0.0729 & 0.0932 & 0.0245 & \\
\hline EU075093.__ziziphus_pubinervis & 0.0750 & 0.0750 & 0.0657 & 0.0682 & 0.0589 & 0.0613 & 0.0570 & 0.0570 & 0.0772 & 0.0772 & 0.06570 & 0.07720 & 0.0823 & 0.0960 & 0.0772 & 0.1105 & 0.0708 & 0.0866 & 0.0613 & 0.1060 & 0.0823 & 0.0910 & 0.0957 & 0.1007 & 0.0820 & 0.0957 & 0.0040 & 0.0245 \\
\hline
\end{tabular}


automatically by applying the Neighbor-Join and BioNJ Algorithms to a matrix of pairwise distances estimated using the Maximum Composite Likelihood (MCL) approach, and then selecting the topology with the superior $\log$ likelihood value. The tree is drawn to scale, with branch lengths measured in the number of substitutions per site (next to the branches). The analysis involved 29 nucleotide sequences. All the positions containing gaps and missing data were eliminated. There were a total of 498 positions in the final dataset. The evolutionary analyses were conducted with the help of MEGA6 [2] Software.

\section{Acknowledgments}

We are thankful to the local people of the Kharpakot VDC of Kavrepalanchok district, Nepal for their cooperation during our field visit in June, 2016.

\section{References}

Bhandari, M. M. and Bhansali, A. K. 2000. Flora of India (Oleaceae-Connaraceae) (ed) Singh, N. P., Vohra, J. N., Hajra, P. K. and Singh, D. K., Botanical Survey of India, Calcutta, India 5: $221-245$.

Bhattarai, K. R. and Pathak, M. L. 2015. A New Species of Ziziphus (Rhamnaceae) From Nepal Himalayas. Indian Journal of Plant Sciences 4 (2): 73.

Chen Y. L. and Chou, P.K. 1979. Materiae Ad Floram Rhamnaceae Sinica Rum. NorthEastern Forestry Institute, Harbin. Bulletin of Botanical Laboratory 5: 88.

Chen, Y.L. and Schirarendin, C. 2007. Ramnaceae. In Flora of China (Hippocastanaceae through Pentaphylaceae), vol. 12 (eds) Wu, Z. and Raven, P. H., St. Louis Missouri Botanical Garden Press. http://flora.huh.harvard.edu/ china/mss/volume 12/Rhamnaceae-MO_ edited.htm accessed on 19 December, 2016.

Grierson, A. J. C. and Long, D. G. 1991. Flora of Bhutan, Rhamnaceae. Royal Botanic Garden, Edinburgh 2, UK (Part 1), 136-141.

Islam, M. B. and Simmons, M. P. 2006. A Thorny Dilemma: Testing Alternative Intrageneric Classifications within Ziziphus (Rhamnaceae). Systematic Botany 31 (4): 826-842.
Li, L., Peng, J. Y., Bai, R. X. and Zheng, B. Q. 2009. The phylogenetic relationships of genus Ziziphus Mill. Native to China based on RAPD analysis. Acta horticulturae (840): 107-116.

Mabberley, J. D. 2008. Mabberley's PlantBook: A Portable Dictionary of Plants, their Classification and Uses. Third edition, Cambridge University Press, UK.

NHPL. 2011. Catalogue of Nepalese Flowering Plants-II (eds) Rajbhandari, K. R., Bhattarai, K. R. and Baral, S. R., Department of Plant Resources, National Herbarium and Plant Laboratories (NHPL), Godawari, Lalitpur Nepal, 210.

NHPL. 2012. Catalogue of Nepalese Flowering Plants-III (ed) Rajbhandari, K. R., Bhattarai, K. R. and Baral, S. R., Department of Plant Resources, National Herbarium and Plant Laboratories (NHPL), Godawari, Lalitpur Nepal, 255.

Outlaw Jr, H. W., Zhang, S., Riddle, K. A., Womble, A. K., Anderson, L. C., Outlaw, W. M., Outlaw, N. N., Outlaw, E. C. and Thistle, A. B. 2002. The jujube (Ziziphus jujuba Mill.): a multipurpose plant. Economy Botany 56 (2): 198-200.

Tamura, K. and Nei, M. 1993. Estimation of the number of nucleotide substitutions in the control region of mitochondrial DNA in humans and chimpanzees. Molecular Biology and Evolution 10: 512-526.

Tamura, K., Stecher, G., Peterson, D., Filipski, A. and Kumar, S. 2013. MEGA6: Molecular Evolutionary Genetics Analysis version 6.0. Molecular Biology and Evolution 30: 27252729.

Xu, B., Gao, X. F. and Zhang, B. 2013. Lespedeza jiangxiensis, sp. nov. (Fabaceae) from China based on Molecular and Morphological Data. Systematic Botany 38 (1): 118-126.

TPL. 2013. The Plant List: A Working List of All Plant Species, Version 1.1 (September, 2013). www.theplantlist.org accessed on 17 December, 2016. 